\title{
Research on Cultivating Innovative and Enterprising Talents of Printing and Packaging in Beijing-Tianjin- Hebei Universities
}

\author{
Cao Guorong, Liu Quanxiao, Zhang Lizheng, Fu Yabo, Cheng Ling \\ School of Printing and Packaging Engineering \\ Beijing Institute of Graphic Communication \\ Beijing, China \\ 1 Xinghua Avenue (Band Two), Daxing, Beijing 102600
}

\begin{abstract}
By studying the system of collaborative innovation mechanism of printing and packaging in Beijing, Tianjin and Hebei universities, the training system of innovation and entrepreneurship and the construction plan of teachers and their implementation measures, we can make the colleges' advantaged resources complementary and shared.So that we can cultivate professional innovative and corporate talents of printing and packaging, who are In line with the Beijing-Tianjin-Hebei integration requirements. And the advanced achievements can be promoted and used between relevant professional industry in universities and colleges in beijing-tianjin-hebei region .
\end{abstract}

Keywords—Beijing-Tianjin-Hebei; collaborative training; printing and packaging; innovation and entrepreneurship

\section{INTRODUCTION}

It is an important task established by the Beijing Institute of Graphic Communication Party Committee in early 2015 that promoting collaborative development of colleges and universities (hereinafter referred to as "colleges and universities") setting up printing or packaging engineering in Beijing-Tianjin-Hebei cooperation. Because of the exactly correct time of co-development of packaging and printing education in Beijing-Tianjin-Hebei cooperation,this work is supposed to be an important task of BIGC to promote.

During just one year, the beginning of 2014 to the end of the year, the collaborative development in Beijing-Tianjin-Hebei cooperation has risen from the national strategy to one of the major national strategies. In April 2015, the Central Political Bureau considered and adopted the "Beijing-Tianjin-Hebei Cooperation and Development Plan", which is the top-level design at the national level. In June, the Ministry of Finance and the State Administration of Taxation issued "the Measures for the Sharing of Tax Revenue in Docking Enterprises Transferfed between Beijing-Tianjin-Hebei and the Development of Industrial”. Some local related policies in Beijing, Tianjin and Hebei have also been introduced, in particular, the trend of "relocation development" of Beijing Universities is highlighted, making governments and universities in Tianjin and Hebei negotiate some docking issues with BIGC, like "relocation development" and printing and packaging talent training.

In April 2014, in order to do some upfront for collaborative development of advanced education and printing and packaging industry in Beijing-Tianjin-Hebei region, BIGC has set up a research group with Beijing press and publication radio and television bureau, Beijing Packaging Association and Beijing Printing Association. They made some preliminary exchanges successively with the local government and the industry in Hebei and Tianjin region. Investigators initially formed the idea of train innovative and entrepreneurial talent depends on the printing and packaging the alliance of the Beijing-Tianjin-Hebei region, relying on printing and packaging education, scientific research and talent advantages, high-end printing and packaging enterprises in Beijing, relying on the national and Beijing municipal teaching and scientific research platform of all kinds of printing and packaging at BIGC.

\section{PRINTING AND PACKAGING INDUSTRY AND EDUCATION IN BEIJING, TIANJIN AND HEBEI}

\section{A. Printing and packaging industry basic situation in Beijing-Tianjin-Hebei region.}

From the perspective of the basic situation of printing and packaging industry in these three areas, printing and packaging industry in Beijing is one of three largest printing and packaging bases in China, the core of the printing and packaging industry in the Bohai Sea region. There are 237 publishing units in Beijing, accounting for nearly half of the total number of publishing units in the country. It is the characteristics of printing industry in Beijing that publication is the mainly part.

Packaging Engineering Professional Teaching Team (Construction) and Research on Cultivating Innovative Talents of Printing and Packaging Specialty in Beijing - Tianjin - Hebei Universities. 
There are many advantaged resources in Beijing printing industry, like high-end printing and packaging demonstration enterprises, printing and packaging advanced and vocational education, printing and packaging scientific research institutions, the main body medium of printing and packaging, international exchange platform of printing and packaging industry.

Package pringting is the backbone industry of printing and packaging in Tianjin. And the output value of packaging printing accounts for $86 \%$ of the whole printing industry. It has a large amount of resources like packaging and printing equipment manufacturing, high-end packaging and printing enterprises, undergraduate and higher professional packaging and printing education, etc.

With the location advantages of being around Beijing and tianjin and all kinds of cost advantages, Hebei province has been the formation of printing and packaging gathering place, including baoding, langfang, zhuozhou, xiongxian county, sanhe, LaoTing and yutian, etc. Some of these enterprises has been in service for the publisher in Beijing, and has absorbed many Beijing spillover of printing and packaging business.

\section{B. Basic Situation of Printing and Packaging Advanced Education in Beijing - Tianjin - Hebei region}

According to the factors of colleges setting up the printing and packaging majors, such as teachers, professional ability, geographical location and depth of cooperation, 10 universities were selected to study, including Beijing Institute of Graphic Communication, Beijing Forestry University, Beijing Technology and Business University, Beijing Union University, Beijing Chemical Engineering University, Beijing Agricultural College, Tianjin University of Science and Technology, Tianjin University of Commerce, North China University of Science and Technology, Hebei Agricultural University. From the perspective of the basic situation of printing and packaging education in Beijing - Tianjin - Hebei region, there are 6 related universities in Beijing, 2 universities in Tianjin , 2 universities in Hebei. Apparently, universities in Beijingis are the core, accounting for two-thirds of those universities. And BIGC is the core of the core. Our school has the longest history of the printing engineering(57 years), national characteristics of professional major, and packaging engineering(26 years), Beijing municipal professional major, and advantaged resourcesm like Beijing practice teaching demonstration center (printing engineering comprehensive training center), Beijing municipal trainning base (Beijing Yachang \& BIGC), Beijing Green Printing and Packaging Industry Technology Research Institute, Beijing Green Printing and Publishing Technology Collaborative Innovation Center, China Printing Museum, etc. With the printing engineering professional "National Excellent Engineer Education and Training Program" project, it is our responsibility to train the printing and packaging innovation and entrepreneurial talent, lead the industry science and technology development.

In addition, there are interconnected organizational advantages in Beijing-Tianjin-Hebei region, including the basis for longterm exchanges and cooperation and common development. For example, BIGC and Tianjin University of Science and Technology has been training graduate students for nearly 10 years. Over the past three years, the two schools exchanged more than 20 undergraduate students majoring in printing and packaging engineering, with cooperation training for 1 year and mutual recognition credits. In addition, Beijing Forestry University has repeatedly invited Professor Cao Guorong to do new technology seminarsof printing and packaging for the packaging engineering students, Professor Zhang Gengmei teach packaging and printing courses, and send graduate students to BIGC in many times to study the stage of cooperation Training. Our school has repeatedly undertaken students in Beijing Forestry University to visit BIGC and other internship practice activities; In addition to teachers exchange visits, many students in North China University of Science and Technology, and Hebei Agricultural University are admitted to our school graduate students every year, promoting the cooperation and communication. In addition, in the process of revising the training program, each college research complement each other, learn from each other, mutual visit experts demonstration study; mutual investigation, learn from each other, ask each other experts to demonstrate learning; The teachers and students took part in all kinds of national packaging design competitions and academic exchanges, learning and competing from each other, forging a deep friendship and so on. With a national strategy to support the industry, the consensus of experts in colleges and universities, a good basis for cooperation, therefore, we have full of confidence and expectations to Beijing-TianjinHebei cooperation in training and packaging innovation and entrepreneurial talent research results reasonably.

\section{RESEARCH ON PRINTING AND PACKAGING PROFESSIONALS}

\section{A. The Beijing-Tianjin-Hebei study of printing and packaging professional cooperative innovation mechanism system}

Combing with the the actual teaching situation of printing and packaging profession in Beijing-Tianjin-Hebei region, in the view of education collaborative development of printing and packaging in Beijing-Tianjin-Hebei region, we are supposed to build "Beijing-Tianjin-Hebei printing and packaging colleges and universities Union" as soon as possible. And relying on "BeijingTianjin-Hebei printing and packaging colleges and universities Union", continue to explore the university to explore the educational resources between the school to build a long-term mechanism, build the mechanism of talent training base outside and vigorously promote the printing and packaging engineering collaborative innovation mechanism system research and implementation, and gradually form the Beijing-Tianjin-Hebei region to build the sharing of institutionalization, continuity and characteristics. 
B. Research of existing teaching resources distribution, explore the printing and packaging professional creative talent cultivation system

Through the visit of the colleges setting up printing and packaging in Beijing-Tianjin-Hebei region, finding out the advantages of the distribution of resources in colleges and universities, we are supposed to provide a solid foundation for the establishment of printing and packaging professional innovation and entrepreneurship training system.

From the requirements of innovative entrepreneurship, give full play to the Beijing-Tianjin-Hebei universities in the printing and packaging engineering professionals to cultivate their own disciplines and professional advantages, reconstruction training program, and actively explore the "double play" talent training model, "X $+\mathrm{Y}+\mathrm{Z}$ "training mode. XYZ, respectively, for the Beijing-Tianjin-Hebei region schools, four years of study in a multi-school, each school for 1-2 years, students from 10 universities in the printing engineering and packaging engineering students, when you enter the school to carry out voluntary reporting and selection by condition.

\section{Research on the Construction of Teaching Staff in Beijing - Tianjin - Hebei Universities}

Through the clear goal of personnel training, organize the professional entrepreneurial spirit of the teacher team of printing and packaging in Beijing-Tianjin-Hebei region, study the teacher-related selection, assessment and incentive mechanism and innovative business philosophy, teaching content, teaching methods, teaching methods and other aspects of the upgrade training program.

\section{CONCLUSION}

Through the research of Beijing-Tianjin-Hebei colleges to cultivate innovative and innovative talents of printing and packaging specialty, this paper solves the problem of differentiating and peculiarities of cultivating innovative entrepreneurial talents and existing university personnel training education system and institutional mechanism; solves the integration of Beijing and Tianjin in the context of the printing and packaging industry and the urgent needs of innovative entrepreneurship; solves the existing faculty can not meet the problem of cultivating innovative entrepreneurship. To "enhance the ability of teachers to innovate and entrepreneurship" as the fundamental, Beijing-Tianjin-Hebei colleges and universities with the "teacher team" construction program, the school together on the road of innovation and development of strong schools, It makes the establishment of "Beijing-Tianjin-Hebei printing and packaging education and coordinated development" as the starting point, the creation of "collaborative training of personnel" new mechanism system, highlight the advantages and characteristics of "innovative entrepreneurship training" as the foothold, to explore the Beijing-Tianjin-Hebei university collaborative training "Innovative entrepreneurial talent" mode of education to meet the industry restructuring and transformation of enterprises to upgrade the demand for innovative entrepreneurship. Through the Beijing-Tianjin-Hebei 10 colleges and universities to cultivate printing and packaging professional innovation and entrepreneurship, we are supposed to achieve the sharing of resources inside and outside the school and mutual development, to provide personnel protection for the transformation and upgrading of BeijingTianjin-Hebei enterprises. 